\title{
Accelerated Life Test of high luminosity blue LEDs
}

\author{
E. Nogueira , V. Orlando, J. Ochoa, A. Fernandez, M. Vazquez
}

\begin{abstract}
A B S T R A C T
A complete Accelerated Life Test on high luminosity blue LEDs is presented. The test was conducted at different temperatures, humidity and current conditions, involving a total of seven individual tests. Life models were obtained for the catastrophic failures of the tests and then a complete temperature, humidity and current model was developed, which enabled the calculation of the life of the LEDs for any of these conditions. Catastrophic failures and model parameters were consistent with earlier results using different high luminosity LEDs. Non-catastrophic failures were modelled with their corresponding luminous power loss on each test, with expected results.
\end{abstract}

\section{Introduction}

In recent years, lighting using LEDs has grown significantly due to its essential advantages such as lower consumption, smaller size and longer lifetime. Related to the lifetime of the LEDs new products must pass a reliability test before they can enter the market. The tests employed by the LED industry, IES LM-80-08 [1], last for a minimum of $6000 \mathrm{~h}$, which can set back the time taken to market a product. Based on the prior works that have reported the manner in which temperature affected the LED lifetime in this study, an accelerated test was achieved under high ambient temperatures [2-5]. In order to correlate the lifetime obtained in the accelerated tests to normal conditions, the Arrhenius model is used. The influence of humidity and bias current is also analysed by obtaining a life model that includes three different parameters, like temperature, drive current and humidity. To the best of our knowledge there is no other life model that includes all three different parameters in this type of LED.

In this study, the tests of both failure modes of the blue LEDs, catastrophic failures (open circuit) and degradation failures, have been studied. The lifetime models for catastrophic and degradation failures are therefore proposed. An analysis of the changes of luminous power versus time is presented, using a fit based on 2nd degree polynomials.

\section{Samples and methods}

The LED samples were in the standard package T-1 3/4 (5 mm) with transparent epoxy resin, InGaN LEDs (blue, $470 \mathrm{~nm}$ wavelength), maximum DC Forward Current $35 \mathrm{~mA}$ and Luminous Intensity $(\mathrm{IF}=20 \mathrm{~mA})$
11,000 mcd. The lead frame used in the LEDs was Ag plated Copper alloy.

In this case study seven ALT (Accelerated Life Testing) tests were performed on blue LEDs, in which each test had 15 LEDs tested inside a pressure cooker under different humidity conditions (55, 70 and $85 \%$ $\mathrm{HR}$ ) and temperatures $\left(120,130\right.$ and $\left.140^{\circ} \mathrm{C}\right)$. They were also tested at three different currents $(10,20$ and $30 \mathrm{~mA})$. The conditions prevailing in each test are presented in Table 1.

The ALT test conditions were planned under the following situations:

- In this work Temperature was the accelerator stress used. The temperature in the ALT was higher than the values specified for working conditions in order to reduce the test times, but low enough to avoid failures that do not appear in normal working conditions. Selected ambient temperature values, from $120^{\circ} \mathrm{C}$ to $140^{\circ} \mathrm{C}$, were in the range of other temperature ALT works in similar LEDs [3-5].

- Related to the bias current and humidity the values selected were below the maximum values of the specification and therefore the accelerator factors resulting from these parameters are not determinant. However, the tests at different values of the bias current and humidity were done to analyse the influence of the different parameters in the lifetime of the LEDs.

\subsection{Failure criterion definition}

The LEDs presented two types of failures: catastrophic, which could be either the short or open circuit conditions; in our tests only the open circuit failures appeared, and all of them were caused by humidity penetration on the anode, producing bonding oxidation between the lead frame and the cathode wire (Fig. 1), and the degradation failures, 
Table 1

Test conditions.

\begin{tabular}{lll}
\hline Temperature $\left({ }^{\circ} \mathrm{C}\right)$ & Current $(\mathrm{mA})$ & Humidity $(\%)$ \\
\hline 120 & 20 & 70 \\
130 & 20 & 70 \\
140 & 20 & 70 \\
130 & 10 & 70 \\
130 & 30 & 70 \\
130 & 20 & 55 \\
130 & 20 & 85 \\
\hline
\end{tabular}

which were a decrease in the luminous power output of the LED compared with the pre-test measurements. ASSIST has defined two values to quantify the failure of an LED [6].

In fact, $50 \%$ of the initial output power for the LEDs were used as indicators and $70 \%$ for general lighting applications; in this study the $70 \%$ value was selected in light of the type of applications for which these LEDs were used. Other studies too have used this value to define degradation failure $[7,8]$.

\section{Catastrophic failure analysis}

\subsection{Temperature tests}

In this section, a life analysis is presented for three different temperatures, a current of $20 \mathrm{~mA}$ and $70 \%$ HR. Fig. 2 shows the Weibull plot for the catastrophic failures on the temperature test and Table 2 lists the corresponding parameters.

The medians obtained in the table have been presented in an Arrhenius plot in order to obtain a model for the current and humidity conditions tested as shown in Eq. (1) and Fig. 3.

$t_{50 \%}=2 \cdot 10^{-10} e^{\frac{0.97}{\pi T}}$

The red line shows the LED life for a temperature of $300 \mathrm{~K}$. An activation energy of $0.97 \mathrm{eV}$ was obtained, similar to the previous results using high luminosity LEDs [2], revealing that the failure mechanism is identical; humidity penetration through the anode terminal.

\subsection{Current tests}

In this section the effect of the bias current in the LEDs is analysed. Three tests were performed, using a temperature of $130^{\circ} \mathrm{C}$, an $\mathrm{RH}$ of

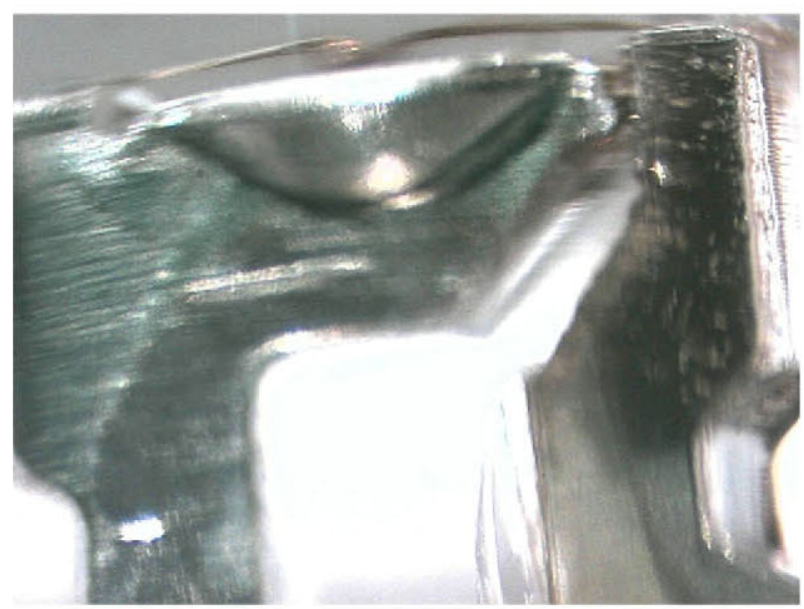

Fig. 1. LED anode oxidation.

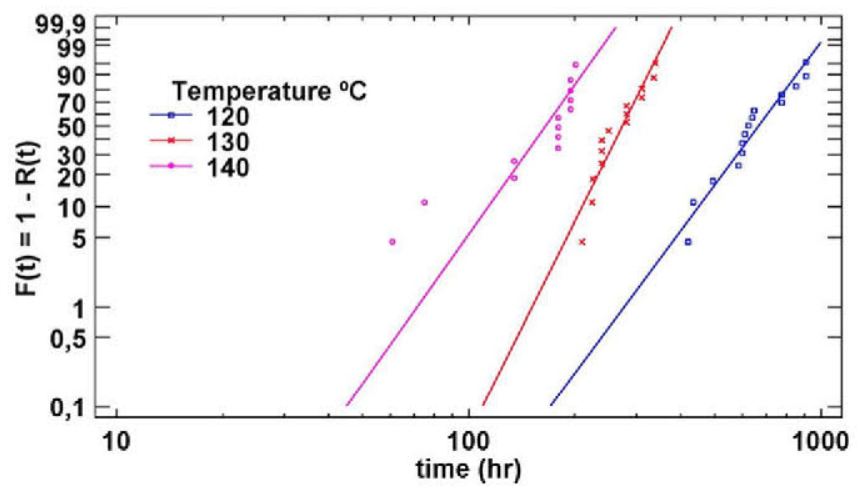

Fig. 2. Weibull plot for temperature tests.

$70 \%$ and three different bias currents of 10,20 and $30 \mathrm{~mA}$. The model giving the best fit is the Inverse Power Law relationship. Fig. 4 shows the failure times and the Weibull plots fitted to each test. Table 3 reveals the shape and scale parameters of the Weibull distribution for all the three tests and medians.

Table 3 shows that for the range of the bias currents tested the variation of the medians is low, indicating that for this current range the influence of the bias current in the degradation of the device is very low. Eq. (2) and Fig. 5 were obtained using the Inverse Power Law relationship.

$t_{50 \%}=706\left(\frac{1}{\mathrm{I}}\right)^{0.34}$ [4].

This influence is similar to the influence reported by other authors

\subsection{Humidity tests}

Finally, the influence of humidity in the life model was analysed. Three tests were performed $(55,70$ and $85 \% \mathrm{RH})$ with a chamber temperature of $130{ }^{\circ} \mathrm{C}$ and a current of $20 \mathrm{~mA}$. In Fig. 6 the failure time for each of the LEDs in the three tests is seen, as well as the fit for each test using a Weibull distribution. Table 4 shows the shape and scale parameters of the Weibull distribution and the medians for the three tests.

The medians indicate that humidity has a greater influence than that of the bias current, as reflected in the model, in which the exponent is much higher in the humidity model. Eq. (3) and Fig. 7 were obtained using Peck's model:

$t_{50 \%}=2.45 \cdot 10^{8}\left(\frac{1}{R H}\right)^{3.19}$

For this test similar results were obtained in [2] with $\mathrm{n}=3.26$.

Table 2

Weibull parameters and median for temperature tests.

\begin{tabular}{llllll}
\hline $\begin{array}{l}\mathrm{T}\left({ }^{\circ}\right. \\
\mathrm{C})\end{array}$ & $\begin{array}{l}\text { Sample } \\
\text { size }\end{array}$ & $\begin{array}{l}\text { Number of } \\
\text { failures }\end{array}$ & $\begin{array}{l}\text { Weibull shape } \\
\text { parameter }\end{array}$ & $\begin{array}{l}\text { Weibull scale } \\
\text { parameter }\end{array}$ & $\begin{array}{l}\text { Median } \\
\text { (h) }\end{array}$ \\
\hline 120 & 15 & 15 & 4.81 & 718.9 & 666.2 \\
130 & 15 & 14 & 7.16 & 288.2 & 273.8 \\
140 & 15 & 13 & 5.03 & 178.3 & 165.7 \\
\hline
\end{tabular}




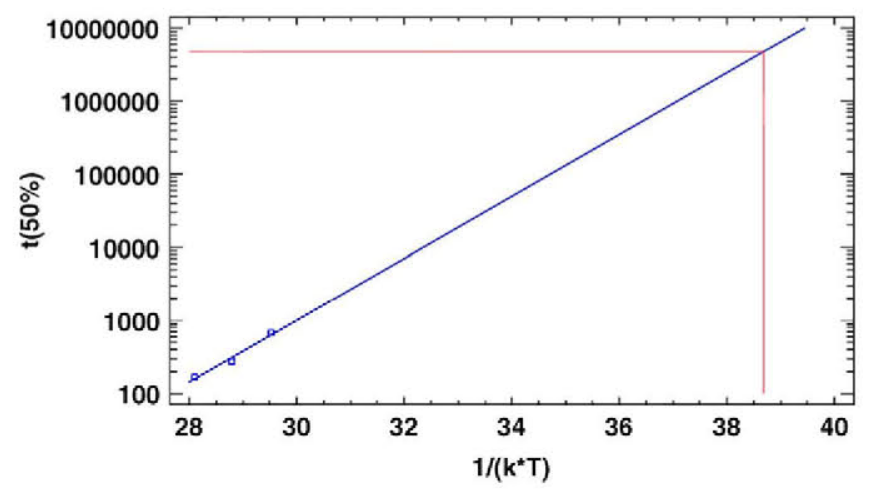

Fig. 3. Arrhenius plot.

3.4. Complete model for temperature, humidity and current for catastrophic failures

Using all the three models obtained previously, a complete model is obtained. This model enables calculation of the life (median) for any of the conditions of temperature, humidity and current.

$t_{50 \%}=4.42 \cdot 10^{-4} * \frac{1}{H^{3.19}} * \frac{1}{\mathrm{I}^{0,34}} * e^{\frac{0.97}{\mathrm{kT}}}$

\section{Degradation analysis}

\subsection{Analysis of the luminous power degradation over time}

In Fig. 8 the normalized luminous power loss versus time [9] is shown. A 2nd degree polynomial fit was used; the $R^{2}>0.95$ was obtained for all cases, showing a very good fit negating the necessity to use the higher degree polynomial fits. Other authors have stated that this power loss is exponential [10], which is an accurate hypothesis for a power loss between $0.9-0.8$ and $0.4-0.3$, although not for the entire range.

In all the cases the luminous power increased until it achieved the maximum after which it began to decrease. The time at which the maximum occurred depended on the test conditions; if the conditions were more severe the maximum appeared earlier [11,12]. The failure time (time at which a $30 \%$ power loss is measured) revealed the identical behaviour: more severe conditions could induce this power loss to occur earlier.

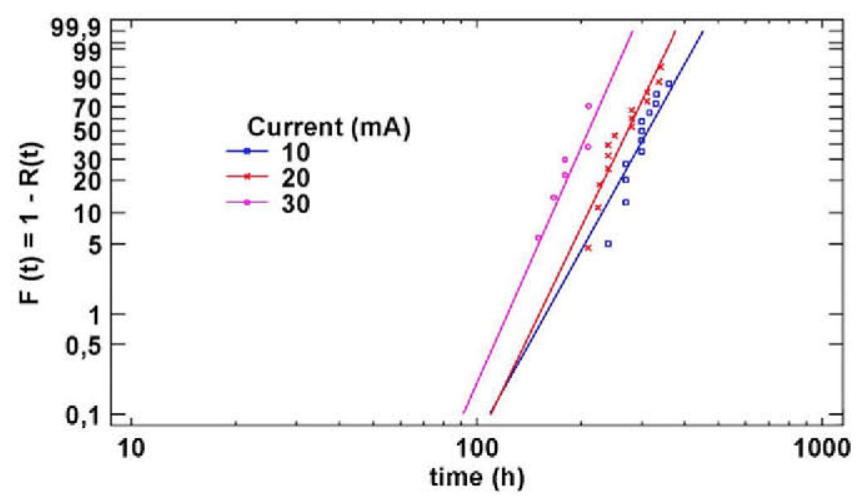

Fig. 4. Weibull plot for current tests.
Table 3

Weibull parameters and median for the current tests.

\begin{tabular}{llllll}
\hline $\begin{array}{l}\text { I } \\
(\mathrm{mA})\end{array}$ & $\begin{array}{l}\text { Sample } \\
\text { size }\end{array}$ & $\begin{array}{l}\text { Number of } \\
\text { failures }\end{array}$ & $\begin{array}{l}\text { Weibull shape } \\
\text { parameter }\end{array}$ & $\begin{array}{l}\text { Weibull scale } \\
\text { parameter }\end{array}$ & $\begin{array}{l}\text { Median } \\
(\mathrm{h})\end{array}$ \\
\hline 10 & 15 & 12 & 6.21 & 331.6 & 312.6 \\
20 & 15 & 14 & 7.15 & 288.1 & 273.7 \\
30 & 12 & 6 & 7.84 & 220.6 & 210.6 \\
\hline
\end{tabular}

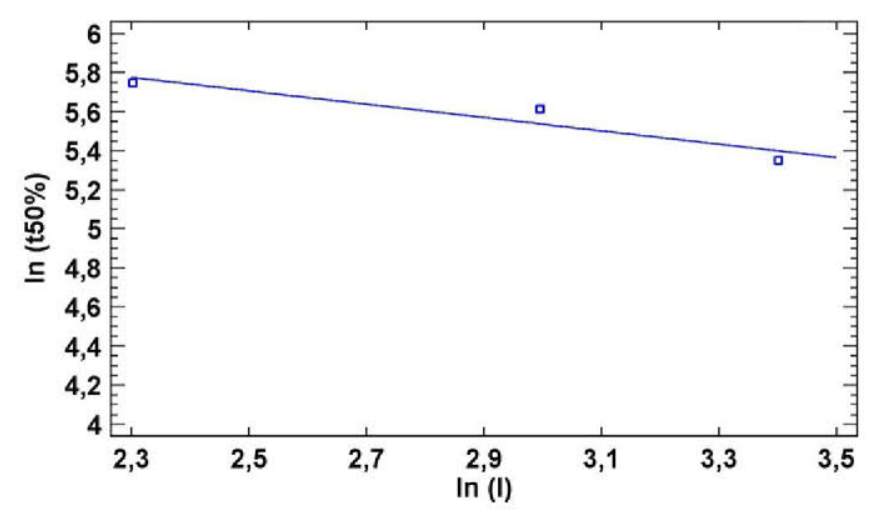

Fig. 5. Inverse Power Law plot.

4.2. Life model for the degradation failures based on temperature, humidity and current

Table 5 shows the results for the Weibull shape parameter, number of failures using the degradation failure criterion and the medians calculated using Weibull's model, employing the identical methodology mentioned in Sections 3.1, 3.2 and 3.3.

Using the medians and Arrhenius, Peck and Inverse Power Law models, a model that allows the calculation of the life of the LEDs in light of the functions of temperature, humidity and current has been obtained; the model is shown in Eq. (5).

$t_{50 \%}=3.42 \cdot 10^{-9} \cdot \frac{1}{H^{2.58}} \cdot \frac{1}{\mathrm{I}^{0,48}} \cdot e^{\frac{1.25}{\pi .1}}$

Values of $1 \mathrm{eV}$ have been reported in [13] for the Arrhenius activation energy. This value is similar to the value of $1.25 \mathrm{eV}$ obtained.

Similar to the catastrophic failures the bias current is the less influential parameter (within the range of the bias current range analysed) and temperature emerged as the parameter with the highest influence on the degradation of the devices.

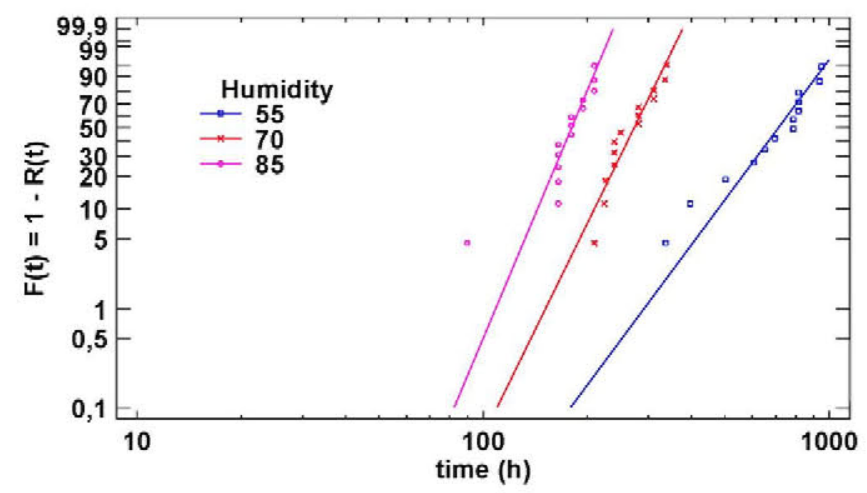

Fig. 6. Weibull plot for humidity tests. 
Table 4

Weibull parameters and median for humidity tests.

\begin{tabular}{llllll}
\hline RH\% & $\begin{array}{l}\text { Sample } \\
\text { size }\end{array}$ & $\begin{array}{l}\text { Number of } \\
\text { failures }\end{array}$ & $\begin{array}{l}\text { Weibull shape } \\
\text { parameter }\end{array}$ & $\begin{array}{l}\text { Weibull scale } \\
\text { parameter }\end{array}$ & $\begin{array}{l}\text { Median } \\
(\mathrm{h})\end{array}$ \\
\hline 55 & 15 & 13 & 4.73 & 772.7 & 715.0 \\
70 & 15 & 14 & 7.16 & 288.1 & 273.8 \\
85 & 15 & 14 & 8.34 & 188.6 & 180.5 \\
\hline
\end{tabular}

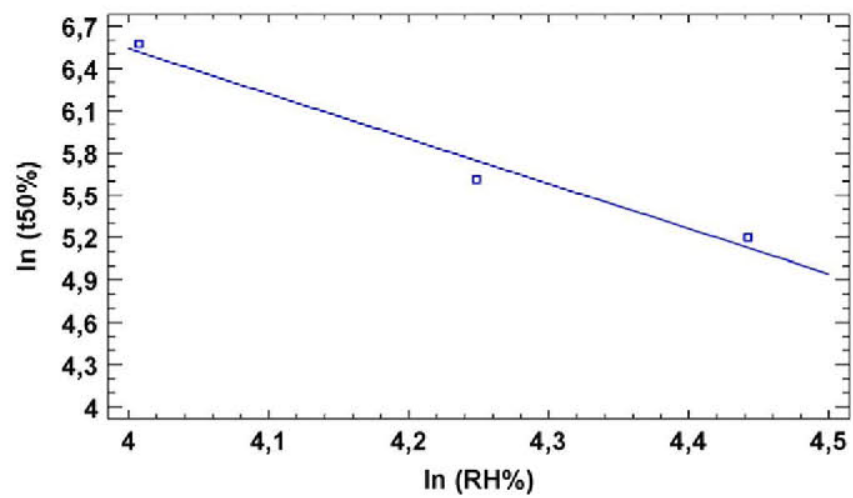

Fig. 7. Peck plot.

\section{Conclusions}

A model that facilitates the calculation of the life of this type of LEDs for different conditions of temperature, humidity and current has been developed.

This model enables the deduction that temperature is the most influential factor in the life of the LED, followed by humidity. Current exerts a lower degree of influence for the range of bias currents analysed.

As in the prior works [2], the catastrophic failures observed were open circuits caused by the humidity penetration on the anode. Catastrophic failures are found to be more common than the degradation failures.

The complete model predicts a median life of $4,627,399 \mathrm{~h}$ of continuous operation under the normal working conditions of $60 \% \mathrm{HR}, 20 \mathrm{~mA}$ and $30^{\circ} \mathrm{C}$.

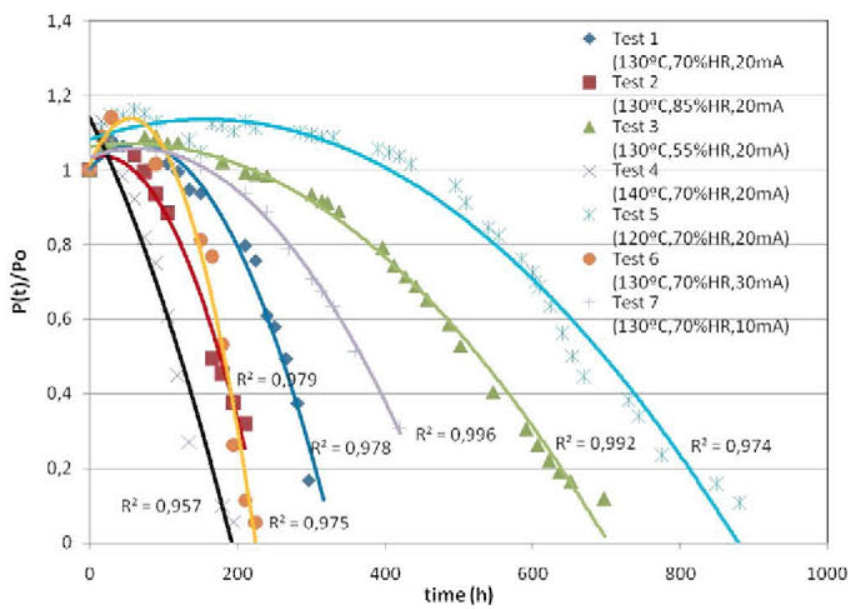

Fig. 8. Normalized luminous power loss versus time.
Table 5

Degradation medians, Weibull shape parameter and number of failures for the tests.

\begin{tabular}{llllll}
\hline $\mathrm{T}{ }^{\circ} \mathrm{C}$ & $\mathrm{HR} \%$ & $\mathrm{I}(\mathrm{mAs})$ & Weibull shape parameter & Number failures & Median $(\mathrm{h})$ \\
\hline 120 & 70 & 20 & 25.96 & 13 & 608.9 \\
130 & 70 & 20 & 21.77 & 14 & 246.0 \\
140 & 70 & 20 & 12.53 & 13 & 102.6 \\
130 & 55 & 20 & 15.07 & 15 & 444.6 \\
130 & 85 & 20 & 12.19 & 13 & 144.2 \\
130 & 70 & 10 & 21.50 & 10 & 308.6 \\
130 & 70 & 30 & 21.14 & 12 & 177.9 \\
\hline
\end{tabular}

The luminous power changes were modelled using the 2nd degree polynomial, with $\mathrm{R}^{2}$ values of over 0.95 in all the cases, implying that the behaviour is not exponential for the whole curve. The exponential fit is valid only for a set range of luminous power losses.

\section{References}

[1] LM80, IESNA. 08, Approved Method for Measuring Lumen Maintenance of LED Light Sources, Illuminating Engineering Society, 2008.

[2] E. Nogueira, M. Vázquez, J. Mateos, Accelerated life test of high luminosity AlGaInP LEDs, Microelectron. Reliab. 52 (9) (2012) 1853-1858.

[3] M.Y. Mehr, W.D. Van Driel, G.Q. Zhang, Reliability and lifetime prediction of remote phosphor plates in solid-state lighting applications using accelerated degradation testing, J. Electron. Mater. 45 (1) (2016) 444-452.

[4] S. Ishizaki, H. Kimura, M. Sugimoto, Lifetime estimation of high power white LEDs, J Light. Vis. Environ. 31 (1) (2007) 11-18.

[5] Y.-H. Yang, Y.-F. Su, K.-N. Chiang, Acceleration factor analysis of aging test on gallium nitride (GaN)-based high power light-emitting diode (LED), Thermal and Thermomechanical Phenomena in Electronic Systems (ITherm), 2014 IEEE Intersociety Conference on, IEEE 2014, pp. 178-181.

[6] ASSIST, LED Life for General Lighting Vol. 1, Issues 1, Febraury 2005 4-5.

[7] S. Koh, W. Van Driel, G.Q. Zhang, Degradation of light emitting diodes: a proposed methodology, J. Semicond. 32 (1) (2011) 014004

[8] J.-M. Kang, et al., Life-time estimation of high-power blue light-emitting diode chips, Microelectron. Reliab. 49 (9) (2009) 1231-1235.

[9] N. Narendran, et al., Performance characteristics of high-power light-emitting diodes, Optical Science and Technology, SPIE's 48th Annual Meeting, International Society for Optics and Photonics 2004, pp. 267-275.

[10] M. Meneghini, L. Trevisanello, G. Meneghesso, E. Zanoni, A review on the reliability of GaN-based LEDs, IEEE Trans. Dev. Mater. Reliab. 8 (2008) 323-331.

[11] K. Strubel, N. Linder, R. Wirth, A. Jaeger, High brightness AlGalnP light-emitting diodes, IEEE J. Sel. Top. Quantum Electron. 8 (2002) 321-332.

[12] P.N. Grillot, M.R. Krames, H. Zhao, S.H. Teoh, Sixty thousand hour light output reliability of AlGaInP light emitting diodes, IEEE Trans. Dev. Mater. Reliab. 6 (2006) $564-574$.

[13] S.M. Moon, Y.D. Kim, S.K. Oh, M.J. Park, J.S. Kwak, Failure analysis of InGaN/GaN high power light-emitting diodes fabricated with ITO transparent p-type electrode during accelerated electro-thermal stress, J. Nanosci. Nanotechnol. 12 (5) (May 2012) 4177-4180. 